\title{
Incidence of ocular side effects of topical $\beta$ blockers in the Netherlands
} Luc M van Beek, Rob J W de Keizer, Bettine C P Polak, Paul R Elzenaar,
Nicolaas J van Haeringen, Aize Kijlstra
Department of Ophthalmology, Leiden University Medical Center, Netherlands $L M$ van Beek R J W de Keizer

Department of Ophthalmology, Free University Hospital, Amsterdam, Netherlands B C P Polak

Tramedico BV, Medical Department, Weesp, Netherlands P R Elzenaar

Netherlands Ophthalmic Research Institute

$L M$ van Beek

$\mathrm{N} J$ van Haeringen A Kijlstra

Institute for Animal Science and Health, Lelystad, Netherlands A Kijlstra

Correspondence to: L M van Beek, MD, Leiden University Medical Center, Department of Ophthalmology, PO Box 9600, 2300 RN Leiden, Netherlands

lmvanbeek@lumc.nl

Accepted for publication 24 February 2000

\begin{abstract}
Background-Several ocular side effects including uveitis, have been reported following topical $\beta$ blocker treatment for glaucoma and ocular hypertension. The incidence of these side effects was investigated in the Netherlands.

Methods-A prospective observational design was used whereby monthly questionnaires were sent to all practising ophthalmologists in the Netherlands during 3 consecutive months. Questionnaires were returned at the end of each month. Any patient whose topical $\beta$ blocker therapy was altered because of an ocular reaction was noted on this questionnaire. Ophthalmologists who did not return their questionnaires were interviewed by telephone at the end of the study period. The number of patients using topical $\beta$ blockers was derived from drug sales figures.

Results-70\% (328/467) of the ophthalmologists in the Netherlands participated in the study. During the 3 month study period 34 cases were reported: 15 patients had periorbital dermatitis, in eight patients eyelids and conjunctiva were affected, in seven patients the conjunctiva was affected, and four patients had punctate keratitis. The calculated incidence of ocular side effects during topical $\beta$ blocker therapy was 1.51 cases/1000 patient years. Conclusion-Topical $\beta$ blocker therapy is associated with few clinically important ocular side effects. No cases of uveitis were reported.

(Br F Ophthalmol 2000;84:856-859)
\end{abstract}

Topically applied $\beta$ adrenergic antagonists $(\beta$ blockers) are the first line of treatment in primary open angle glaucoma and ocular hypertension. Safety of topical $\beta$ blockers is mainly determined by their systemic $\beta$ blocking effects. The bronchoconstriction and cardiac arrhythmias caused by topical $\beta$ blockers may be life threatening. ${ }^{1}$ However, ocular side effects may also necessitate discontinuation or changing of topical $\beta$ blocker therapy.

Various ocular side effects have been reported after the use of topical $\beta$ blockers. Blepharoconjunctivitis, conjunctivitis, and punctate keratitis have been described in clinical trials. ${ }^{2}$ In these trials, discontinuation of topical $\beta$ blockers because of ocular side effects ranged from $0 \%$ to $4.3 \%$, independent of dose or which $\beta$ blocker was used. ${ }^{34}$

Other ocular side effects have only become apparent through case reports in the medical literature. These side effects include pseudoocular cicatricial pemphigoid, ${ }^{5}$ conjunctival keratinisation, ${ }^{6}$ and anterior uveitis. ${ }^{7}$ Although anterior uveitis has been described after timolol ${ }^{8}$ and betaxolol use, ${ }^{9}$ its occurrence is best documented after metipranolol use. ${ }^{70-13}$ In three different retrospective studies the reported incidence of metipranolol associated uveitis varied from $6 / 1000$ patients $^{7}$ to less than $1.87 / 1000$ patient years. ${ }^{14} 15$

To our knowledge, except for uveitis, no incidence figures of ocular side effects of topical $\beta$ blockers are available for the general patient population. Therefore, we undertook a observational, nationwide study to determine the incidence of ocular side effects, including uveitis, of topical $\beta$ blockers in the Netherlands. This study shows that 1.5 cases of ocular side effects of topical $\beta$ blockers per 1000 patient years can be expected.

\section{Methods}

During three consecutive months (April, May, June 1997) all practising ophthalmologists in the Netherlands received a monthly questionnaire. Addresses of ophthalmologists were obtained from the Dutch Ophthalmological Society (NOG) of which virtually all ophthalmologists are member in the Netherlands. At the end of each month the questionnaires were returned. All patients who were diagnosed as having ocular side effects associated with topical $\beta$ blocker use in that month, were noted on this questionnaire. Information about systemic diseases, patient characteristics (age, sex), $\beta$ blocker used, period of time that the $\beta$ blocker had been used, co-medication, type of ocular reaction, and improvement after discontinuation of the drug was reported on this questionnaire.

To achieve a high response rate to our questionnaire, we needed a simple and unambiguous definition of ocular side effects of topical $\beta$ blockers. Ocular side effects were defined as any alteration of topical $\beta$ blocker medication because of an ocular reaction. Alterations that were made because of inefficacy of $\beta$ blocker therapy were not included in this study. In the Netherlands $\beta$ blockers are available only on medical prescription. Alterations that were made because of systemic side effects of topical $\beta$ blockers fell beyond the scope of this study.

Ocular side effects can be caused both by the active compound or by one of the auxiliary components in the eye drop. Because the objective of our study was to determine the incidence of ocular side effects of topical $\beta$ blockers as they are used in the Dutch patient 
population, no distinction was made between reactions to the different components.

Ophthalmologists who did not return their questionnaires were interviewed by telephone at the end of the three months' study period. In these interviews we asked whether the ophthalmologist had encountered any ocular side effect of topical $\beta$ blocker therapy during the study period. If the answer was negative then the interview was ended, if the answer was positive the same information as with the questionnaire was collected.

In the Netherlands, all sales of pharmaceutical wholesalers and pharmaceutical industries to local pharmacies are recorded. Sales figures during the study months of all $\beta$ blocking drugs for ophthalmic use (including all brands and generics) were used to estimate the number of patients using topical $\beta$ blocker medication (Pharm inform BV, FI-rom, June 1997). It was assumed that one patient uses one vial of ophthalmic $\beta$ blocker in 1 month.

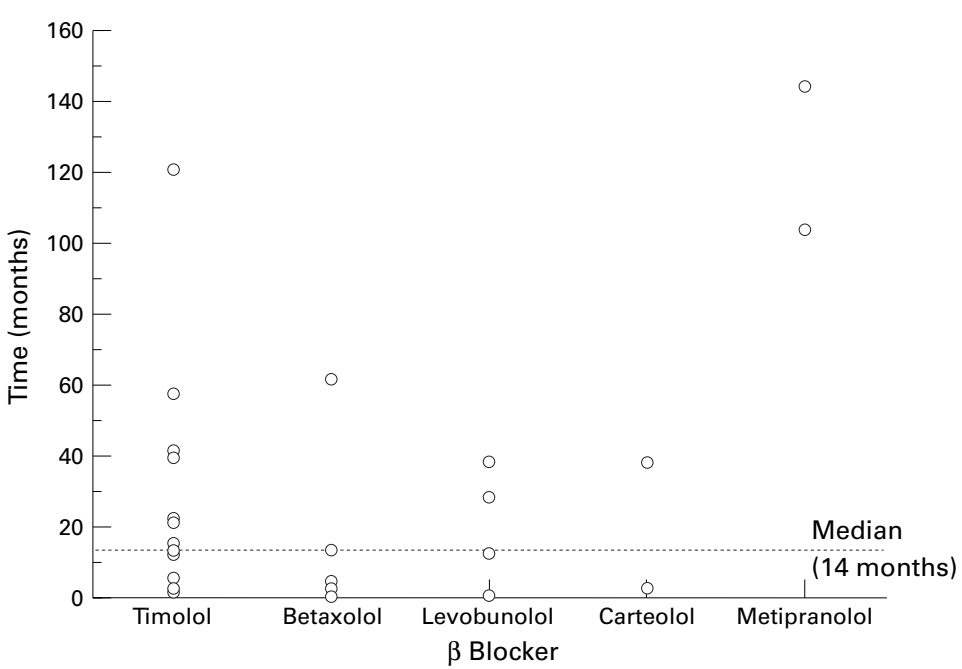

Figure 1 Time that patients used the topical $\beta$ blocker before it was altered because of ocular side effects. For seven patients this information could not be obtained $(n=27)$. Median time the patients used their topical $\beta$ blocker was 14 months (range 1-144 months).

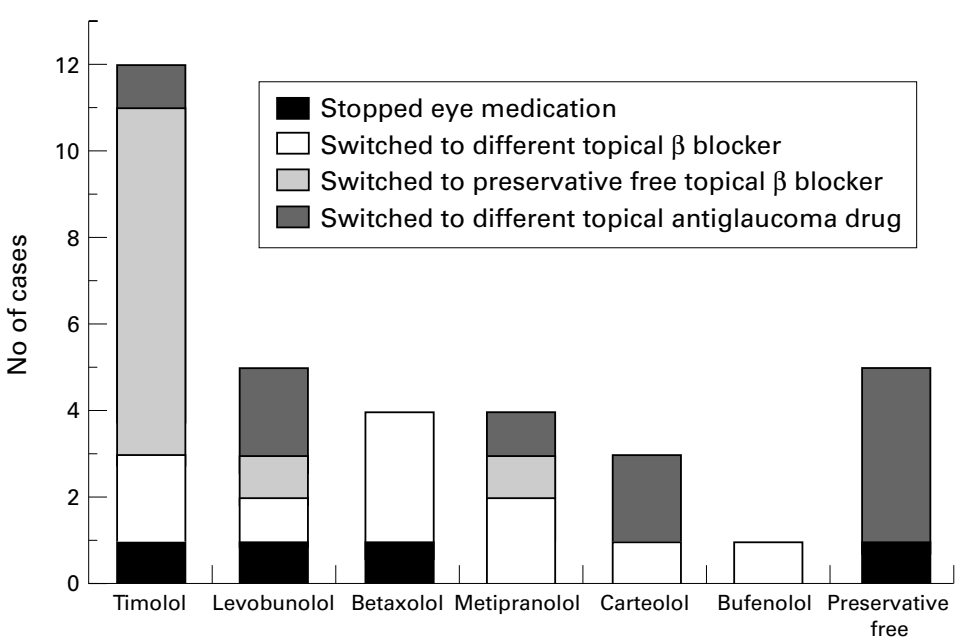

Figure 2 Switches made in topical $\beta$ blocker therapy because of an ocular side effect $(n=34)$. Preservative free denotes all patients altering their preservative-free $\beta$ blocker medication because of an ocular side effect. In this latter group, four patients used preservative-free timolol and one patient used preservative-free metipranolol. Whether the patient was prescribed a different $\beta$ blocker, a preservative-free $\beta$ blocker, a different topical antiglaucoma drug, or stopped topical antiglaucoma therapy is also shown.

\section{Results}

Information was obtained from 365 of the 467 practising ophthalmologists in the Netherlands $(78.2 \%)$. Of the responding ophthalmologists $37(10.1 \%)$ did not participate in the study for various reasons. Information obtained from $328(70.1 \%)$ ophthalmologists in the Netherlands could be used in the study.

During the study period we received information on 34 patients who met our definition of an ocular side effect. Mean age of the patients was 71.3 years, there were 12 men and 22 women. Patients with ocular side effects had used their topical $\beta$ blocker for a median time of 14 months (range 1-144 months, Fig 1). In 28 patients clinical improvement occurred after alteration or cessation of the $\beta$ blocker. No follow up was available for the remaining six cases.

No cases of uveitis were reported. Most often the eyelids were affected (15 patients, $44 \%$ ), these patients usually had periorbital dermatitis or blepharitis. In eight patients $(23 \%)$ both conjunctiva and eyelids were affected; these patients had blepharoconjunctivitis or periorbital dermatitis combined with conjunctivitis or conjunctival hyperaemia. Of seven patients $(21 \%)$ only the conjunctiva was affected; these patients had conjunctivitis or conjunctival hyperaemia. The cornea was affected in four patients $(12 \%)$; all these patients had punctate keratitis.

Analysis of the alterations of topical $\beta$ blocker medication showed the following data (Fig 2). In 12 patients timolol medication was altered. In the majority of these patients (eight) timolol was replaced by a preservative-free timolol formulation. Levobunolol medication was changed in five patients. Both betaxolol and metipranolol medication were changed in four patients. Carteolol medication was changed in three patients. In one patient the bufenolol medication was replaced by another $\beta$ blocker. From the telephone inquiries it appeared that ophthalmologists often hold the preservative responsible for the occurrence of ocular side effects. However, in five patients, who already used either preservative-free timolol (four patients) or preservative-free metipranolol (one patient), ocular side effects necessitated a change in medication. Preservative-free $\beta$ blockers were most often replaced by a different topical antiglaucoma drug (dorzolamide or latanoprost).

Five patients, four on timolol and one on carteolol, used additional topical antiglaucoma drugs besides their topical $\beta$ blocker. Two patients used one additional topical antiglaucoma drug and three patients used two additional topical antiglaucoma drugs. These drugs were dipifevrin (two patients) dorzolamide (two patients) carbacholine (one patient), pilocarpine (one patient), apraclonidine (one patient), and guanethidine/adrenaline (epinephrine) combination (one patient). In one patient, only the $\beta$ blocker medication was altered, while the additional topical medication was continued. In three patients both the topical $\beta$ blocker and one additional topical medication were altered. In one patient the $\beta$ 
Table 1 Calculated incidence of ocular side effects of topical $\beta$ blockers

\begin{tabular}{lccl}
\hline$\beta$ Blocker & Cases* $^{*}$ & $\begin{array}{l}\text { Vials sold during } \\
\text { study periodt }\end{array}$ & $\begin{array}{l}\text { Incidence (cases/1000 patient years) } \\
\text { (95\% confidence interval) } \neq\end{array}$ \\
\hline bufenolol & 1 & 2289 & $5.24(0,15.51)$ \\
metipranolol & 5 & 14288 & $4.20(0.52,7.88)$ \\
carteolol & 3 & 13620 & $2.64(0,5.63)$ \\
levobunolol & 5 & 29611 & $2.03(0.25,3.81)$ \\
timolol & 16 & 151434 & $1.27(0.65,1.89)$ \\
betaxolol & 4 & 58478 & $0.82(0.02,1.60)$ \\
total & 34 & 269720 & $1.51(1.00,2.02)$
\end{tabular}

${ }^{\star}$ Cases were defined as any patient whose topical $\beta$ blocker therapy was altered because of an ocular reaction open to objectification by the ophthalmologist.

†Sales figures of topical $\beta$ blockers were used to estimate the number of patients using topical $\beta$ blockers. It was assumed that one patient uses one vial of $\beta$ blocker in 1 month.

$\ddagger$ No significant differences were found between $\beta$ blockers.

blocker medication and two different additional topical eye medications were altered.

During the study period, a total of 269720 vials of $\beta$ blocking agents for ophthalmic use were sold in the Netherlands. $\beta$ Blockers are available only on medical prescription at pharmacies. Vials are packaged to last 1 month. Extrapolation of these data indicates that 89907 individuals in a population of 15608 591 (CBS Voorburg), used a topical $\beta$ blocker during the study period. The incidence of ocular side effects to topically applied $\beta$ blocking drugs in this study can thus be calculated as $1.51 / 1000$ patient years for the total patient population using a topical $\beta$ blocker. Incidence calculated for the different $\beta$ blockers, varied from 0.82 (betaxolol) to 5.24 (bufenolol) cases/1000 patient years but these differences were not statistically significant (Table 1 ).

\section{Discussion}

This study shows that clinically relevant ocular side effects associated with topical $\beta$ blockers rarely occur. Reactions that did occur in our study most often involved the eyelids and conjunctiva, the cornea was affected in only a few cases. No cases of uveitis were reported whereas Akingbehin and Villada $^{7}$ have reported an incidence of metipranolol associated uveitis of $6 / 1000$ patients. However, high incidence rates for metipranolol associated uveitis have never been found outside of the United Kingdom. Kessler and $\mathrm{Christ}^{14}$ found an incidence rate of $0.5 / 1000$ patient years in Germany and in the United States, Beck et $a l^{15}$ did not find any case of uveitis associated with metipranolol use in a sample of 1972 patient years. Similarly, in our sample of 1191 patient years of metipranolol use no cases of uveitis were reported.

Conjunctivitis and periorbital dermatitis after topical $\beta$ blocker use can be caused by hypersensitivity to the preservative or to the $\beta$ blocker itself. ${ }^{16}$ Because the aim of our study was to determine the incidence of ocular side effects of topical $\beta$ blockers as they are used in the general patient population, no distinction was made between reactions to these two different components. Benzalkonium chloride is used as preservative in all commercially available preserved $\beta$ blockers for topical use. In the present study patients switching to a preservative-free formulation are presumably diagnosed by the ophthalmologist as being hypersensitive to benzalkonium chloride. How- ever, skin tests were not routinely performed to confirm this diagnosis. Contact hypersensitivity to benzalkonium chloride can cause (kerato)conjunctivitis and contact dermatitis of the eyelids. ${ }^{16}$ In patients with various forms of conjunctivitis or contact dermatitis, a sensitisation rate of approximately $6 \%$ to benzalkonium chloride has been found. ${ }^{17} 18$ Patients who discontinued their preservative-free topical $\beta$ blocker in the present study because of ocular side effects may have been sensitised to the $\beta$ blocker itself. Contact hypersensitivity has been described for all $\beta$ blocking agents registered for topical use in the Netherlands except carteolol. ${ }^{18}$

Several factors may have biased our results. Firstly, $30 \%$ of the ophthalmologists in the Netherlands did not participate. However, it may be argued that ophthalmologists who did not encounter any cases of ocular side effects to topical $\beta$ blocker therapy during the study period are less likely to return the questionnaire than ophthalmologists who did encounter such cases. This was supported by the fact that telephone interviews with ophthalmologists who had not returned their questionnaire, yielded no additional cases of ocular side effects. Other than this, we do not know whether responding ophthalmologists differed from non-responding ophthalmologists, although we have no reason to think they did. Therefore, bias from non-participation probably has exerted only a minimal effect on the results.

Another factor of bias may have come from the fact that some patients used additional topical eye medication or systemic medication besides their topical $\beta$ blocker medication. In four patients not only was the topical $\beta$ blocker medication altered but also one or two additional eye medications. The ocular side effects of these four patients, therefore, may not have been caused by the topical $\beta$ blocker. Another two patients used systemic as well as topical $\beta$ blockers. Systemic $\beta$ blockers have been reported to reduce tear production ${ }^{19}$ and glaucoma itself has also been associated with a decreased tear production. ${ }^{20}$ This may aggravate ocular side effects caused by the eye drops.

Another factor of bias may have been misdiagnosis. Because the study was designed to interfere as little as possible with the day to day practice of the responding ophthalmologists, the diagnosis of ocular side effect was not verified by a rechallenge or skin testing. However, symptoms improved in all patients, in whom follow up was available $(n=28)$, after the suspected $\beta$ blocker was changed for another antiglaucoma therapy.

In estimating the number of patients using topical $\beta$ blockers in the Netherlands the following bias may have been introduced. We assumed that patients use one vial of $\beta$ blockers in 1 month. However, patients may use a vial for a longer or shorter period. In the Dutch health care system costs for $\beta$ blocker therapy are completely reimbursed, except for preservative-free formulations, which are partly reimbursed. $\beta$ Blockers are packaged to last a month and it is recommended to patients 
to start on a new vial every month. If patients use a vial longer than one month the incidence per patient years will decrease; obviously, the incidence per vial remains the same.

Furthermore, a factor that may have influenced our result was that we based our calculation of the number of patients on topical $\beta$ blocker medication on drug sales from industries and wholesalers to local pharmacies. However, these sales figures reliably reflect the sales to patients because in the Netherlands local pharmacies do not keep large stocks, thanks to a dense distribution network. This was confirmed by the fact that no substantial differences were noticed in quarterly sales figures of topical $\beta$ blockers throughout the year. As mentioned previously, in the Netherlands patients can only obtain topical $\beta$ blockers on medical prescription via local pharmacies.

Ophthalmologists who failed to return their questionnaires were interviewed at the end of the 3 month study period. In recalling ocular side effects from the past 3 months, bias may have been introduced to our results.

The overall effect of bias in our study may have resulted in a small underestimation of the incidence. The incidence we have found of $1.51 / 1000$ patient years should therefore be considered as a minimum.

We conclude that topical $\beta$ blockers cause 1.51 cases $/ 1000$ patient years of ocular side effects. In our study none of the topical $\beta$ blockers gave rise to (anterior) uveitis. When new drugs for the treatment of glaucoma are compared with $\beta$ blockers, safety, tolerance, comfort, and costs should be considered as well as clinical efficacy.

This research was supported by a grant from Dr Gerhard Mann GmbH, Germany, and Tramedico BV, Netherlands.

1 Nelson WL, Fraunfelder FT, Sills JM, et al. Adverse respiratory and cardiovascular events attributed to timolol ophthalmic solution, 1978-1985. Am $\mathcal{f}$ Ophthalmol 1986;102:606-11.

2 Weinreb RN, Caldwell DR, Goode SM, et al. A doublemasked three-month comparison between $0.25 \%$ betaxolol suspension and $0.5 \%$ betaxolol ophthalmic solution. Am $\mathcal{F}$ Ophthalmol 1990;110:189-92.

3 Krieglstein GK, Novack GD, Voepel E, et al. Levobunolol and metipranolol: comparative ocular hypotensive efficacy, safety, and comfort. Br f Ophthalmol 1987;71:250-3.

4 Denffer H. Efficacy and tolerance of metipranolol: results of a multi-center long term study. In: Merte HJ, ed. Metipranolol. New York: Springer-Verlag,1983:121-5.

5 Fiore PM, Jacobs IH, Goldberg DB. Drug-induced pemphigoid. A spectrum of diseases. Arch Ophthalmol 1987;105:1660-3.

6 Derous D, de Keizer RJ, de Wolff-Rouendaal D, et al. Conjunctival keratinisation, an abnormal reaction to an ocular beta-blocker. Acta Ophthalmol 1989;67:333-8.

7 Akingbehin T, Villada JR. Metipranolol-associated granulomatous anterior uveitis. Br f Ophthalmol 1991;75:519-23.

8 Zimmerman TJ, Baumann JD, Hetherington J Jr. Side effects of timolol. Surv Ophthalmol 1983;28(Suppl):24351.

9 Jain S. Betaxolol-associated anterior uveitis. Eye 1994;8: 708-9.

10 Burvenich $\mathrm{H}$. Metipranolol associated granulomatous anterior uveitis: not so uncommon as thought. Bull Soc Belg Ophtalmol 1995;257:63-6.

11 Melles RB, Wong IG. Metipranolol-associated granulomatous iritis. Am f Ophthalmol 1994;118:712-15.

12 Watanabe TM, Hodes BL. Bilateral anterior uveitis associated with a brand of metipranolol. Arch Ophthalmol 1997;115:421-2.

13 Patel NP, Patel KH, Moster MR, et al. Metipranololassociated nongranulomatous anterior uveitis. $A m \quad \mathcal{F}$ Ophthalmol 1997;123:843-3.

14 Kessler C, Christ T. Incidence of uveitis in glaucoma patients using metipranolol. F Glaucoma 1993;2:166-70.

15 Beck RW, Moke P, Blair RC, et al. Uveitis associated with topical beta-blockers. Arch Ophthalmol 1996;114:1181-2.

16 Herbst RA, Maibach HI. Contact dermatitis caused by allergy to ophthalmics: an update. Contact Dermatitis 1992; 27:335-6.

17 Rudzki E, Kecik T, Rebandel P, et al. Frequency of contact sensitivity to drugs and preservatives in patients with conjunctivitis. Contact Dermatitis 1995;33:270.

18 Perrenoud D, Bircher A, Hunziker T, et al. Frequency of sensitization to 13 common preservatives in Switzerland. Swiss Contact Dermatitis Research Group. Contact Dermatitis 1994;30:276-9.

19 O'Donnell BF, Foulds IS. Contact allergy to beta-blocking agents in ophthalmic preparations. Contact Dermatitis 1993;28:121-2

20 Petounis AD, Akritopoulos P. Influence of topical and systemic beta-blockers on tear production. Int Ophthalmol 1989;13:75-80.

21 Kuppens EV, van Best JA, Sterk CC, et al. Decreased basal tear turnover in patients with untreated primary openangle glaucoma. Am f Ophthalmol 1995;120:41-6. 